\title{
Diagnostic strategies for the repair intervention on churches damaged by earthquakes: the Toscolano Maderno Monumental Complex
}

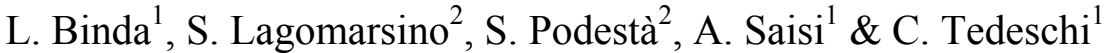 \\ ${ }^{I}$ DIS, Department of Structural Engineering, Politecnico of Milan, Italy \\ ${ }^{2}$ DISEG, University of Genova, Italy
}

\begin{abstract}
This paper describes the methodology applied to two churches of the Garda area damaged by the 2004 earthquake in order to define the repair intervention. After interpretation of the damage causes, based on an accurate onsite survey and documentary research, the intervention strategies were supported by an onsite testing campaign.

Keywords: seismic vulnerability, diagnosis, stone masonry.
\end{abstract}

\section{Introduction}

At the end of 2004 an earthquake (5.2 on the Richter scale) hit the eastern part of the Lombardy Region in Northern Italy, beside the Garda Lake. No casualties occurred luckily, but many buildings were damaged and peculiarly affected was the cultural heritage (Binda [1]).

The Authors were asked by the parish of Toscolano Maderno to carry out a preliminary after earthquake investigation on the Monumental Complex (Fig. 1), composed by two churches, St Andrew's church and the Immacolata church.

The aim was to assess the state of damage of the structures and the properties of the materials as a base for the repair and seismic improvement interventions. This was carried out according to the new Italian Seismic Code. The churches were built in different centuries and show several construction typologies.

The investigation methodology was adopted by the Authors since the beginning of the 1990s and calibrated in different on site investigations on historic masonry buildings in the Umbria region after the earthquake of 1997 (Binda [2]) and in the Liguria region. It is based on the principle that knowledge 
is fundamental for the choice of suitable techniques and materials aimed to the preservation and damage prevention of the cultural heritage. The earthquake that struck Umbria and the Marche regions in 1997 gave the occasion to learn that the lack of knowledge on the material and structural behaviour of the existing buildings was, and still is, the main cause of inappropriate choices for the intervention techniques.

When dealing with churches as monumental buildings, a detailed investigation is needed in order to accomplish both the conservation demands due to their historic-artistic value, and the safety requirements connected with their public function (Binda [3, 4]). The experience in seismic areas showed that this type of buildings is subjected to typical and repetitive damage mechanisms (Doglioni [5], Lagomarsino [6]), as: the façade overturning, the in plane damage of the lateral walls, the damage of the apse and of the bell tower, etc.

\section{Buildings description}

The Monumental Complex of Toscolano Maderno composed of two churches and the rectory, is an important monument of the Garda Lake area.

St Andrew's church was built in the XII ${ }^{\text {th }}$ century on previous buildings with reused elements of the Roman time, as well (Fig. 2). Meaningful transformation were carried out during the centuries: the insertion of a chapel in the right side of the church in the 1343, demolished in the 1962; the construction of the façade, of the bell-tower and of the columns in the 1469; the substitution of the timber trusses with vaults in the 1573 and successively (1580-1605) the addition of further lateral chapels. In the ' 60 s the crypt was reinforced with a heavy structure in r.c.

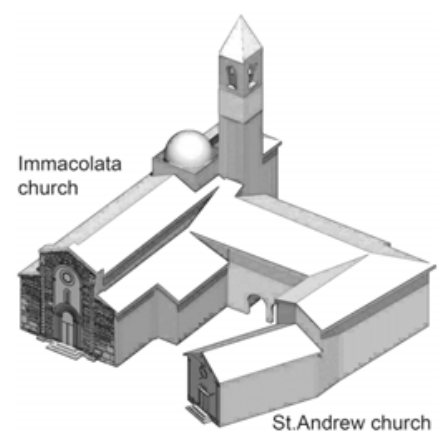

Figure 1: View of the Figure 2: Monumental Complex

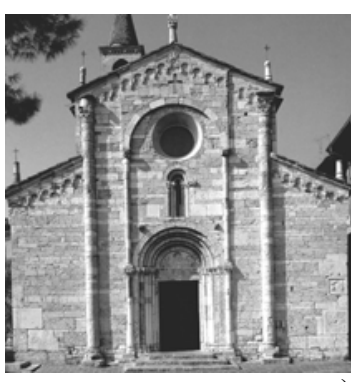

a)

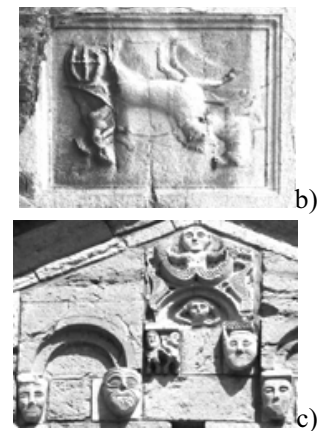

Immacolata Church was built in the 1605 as a baptistery, and successively modified in 1675. A 1929 intervention modified the church as it appears today: in the façade the cornice was removed, the window transformed in an oculus and the perimeter wall was substitute by a steel railing (Fig. 3). Interventions were carried out in the ' $90 \mathrm{~s}$ with the insertion of buttress corresponding to the apse. 

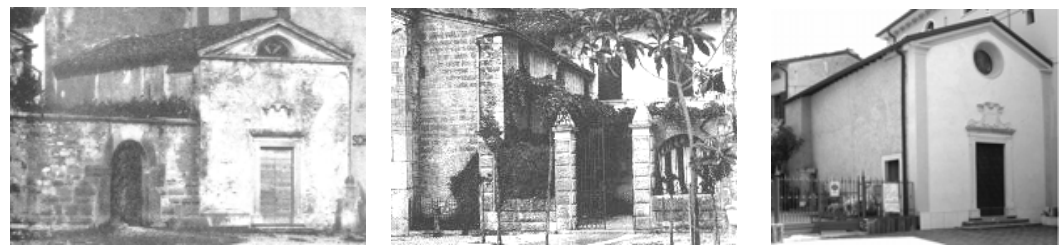

Figure 3: Immacolata church: evolution from the 1929 to the current situation.

\section{Investigation program}

The investigation was carried out following the same procedure for the churches after the: archive documentary research, geometrical and crack pattern survey and interpretation, definition of the possible collapse mechanisms, mechanical characterization of the masonry through flat-jack tests, use of sonic tests to define the density of the walls, individuation of the masonry section typology by sampling, ultrasonic tests on stone columns, vibration tests on tie rods, definition of mortar and stone properties sampled from the walls through chemical, physical and mechanical laboratory tests.

As a first step to provide a design for repair and preservation of the damaged churches a preliminary in-situ survey was considered useful to obtain details on the geometry of the structure, identifying irregularities (vertical deviations, rotations, etc.) and to single out the parts where more accurate investigations was needed. The building may have been subjected to the addition of several volumes in different times, and the possible discontinuities between the different volumes could affect the overall seismic behaviour. Therefore, for a reliable interpretation of the signs of damage, the geometrical survey is not enough but also the historic evolution of the structure in its complexity has to be investigated. Furthermore, this information, together with an evaluation of the quality of the connections, is very important for the structural control of the building and the intervention strategy.

The historic evolution of the buildings was evaluated by documentary research, but also by the observation of constructive details, and by considering the building as subdivided into homogeneous macroelements for analytical purposes. Critical connections between macroelements needed to be investigated, in order to clarify the phases of expansion and transformation of the complex. This information, together with an evaluation of the quality of the connections, is very important for the structural control of the building, peculiarly from the seismic point of view. The bearing walls of the churches were all made in stone masonry, two leaf walls with rather regular (St Andrew's church) or irregular stones (Immacolata church) and apparently built with different construction techniques. On the contrary, the stones come from local quarries and are rather similar; the same can be said for the mortars. The investigation was based on a methodology, which was proposed by the Authors for the vulnerability study of historic centres in seismic areas. 

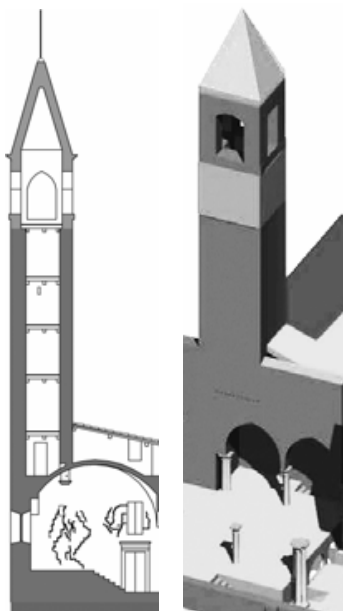

Figure 4: Detail of the bell-tower section and localisation.

The preliminary phase gave important information on vulnerable points and construction anomalies: in the case of St Andrew's the bell-tower load, built in a second time, rests on the apse walls and on a column (Fig. 4).

\subsection{Study of the masonry components and morphology}

The inspection of the surface texture gives only general information about the masonry characteristics. The most important parameter in the evaluation of the masonry quality is the cross section morphology. A regular surface texture can hide a weak masonry structure as often happens in rubble masonry where the external leaf is often regular.

A complete characterization of the wall was achieved by surveying the morphology of the wall cross section, understanding whether the masonry was made of one or more leaves and the leaves were connected and by measuring the sonic velocity, the state of stress, the modulus of elasticity, the coefficient of lateral expansion, the mortar and stones chemical, physical and mechanical properties. Four subsequent steps are usually followed in the same area: (i) sonic tests by transparency on a grid of $75 \times 75 \mathrm{~cm}$, (ii) single and double flat-jack test, (iii) survey of the masonry morphology and material sampling, (iv) repositioning of the stones in the wall.

\subsubsection{Flat jack and sonic test}

According to the low budget allocated by the single churches, only few flat-jack and sonic tests were carried out after a very accurate choice of the test positions; in addition some ultrasonic tests for detecting the columns integrity were performed. Systematically, the testing points were chosen in the most representative parts of the bearing walls: taking into account that the façade is usually made of better masonry, the lateral bearing walls were chosen. The tests were carried out mainly on the outer face of the wall, since the inner one was usually decorated 
with frescos and paintings that could not be damaged. The complementary use of sonic and double flat jack test allows one to qualify the masonry characteristics. According

Preliminary application of sonic tests was useful to control eventual anomalies like the presence of chimney flues or other voids. In fact, the masonry morphology can affect the results.

Fig. 5 shows the results of sonic tests and double and single flat jack on the St Andrew's and Immacolata church. The behaviour is very different: the St Andrew's church is characterised by better behaviour and probably higher strength (Fig. 6) but with an apparently lower compactness of the material, as appear from the average low value of the sonic test. This fact was explained only after a local inspection.

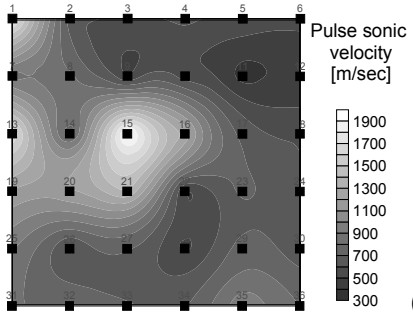

(a)

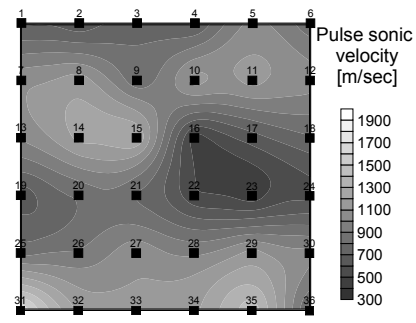

Figure 5: $\quad$ Sonic test results: (a) St Andrew's and (b) Immacolata church.
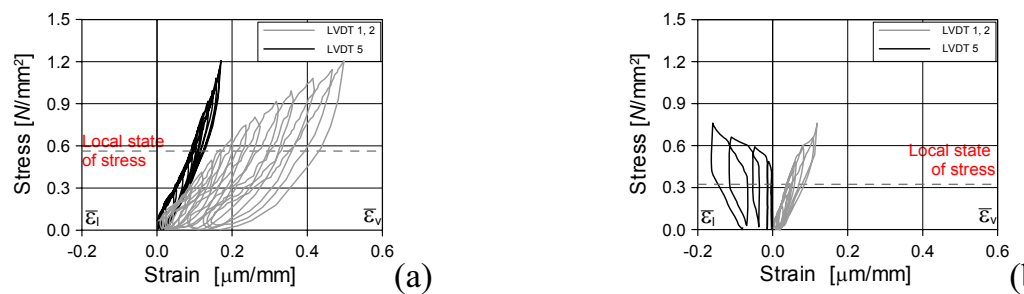

(b)

Figure 6: $\quad$ Flat jack test. (a) St Andrew's and (b) Immacolata church.

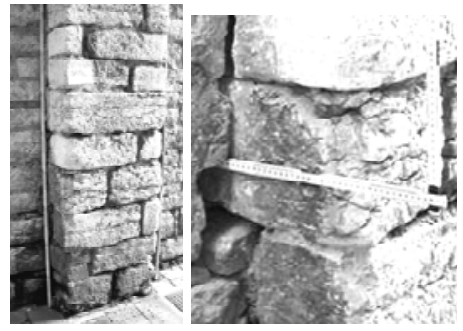

Figure 7: The inspection shows good connection of the plaster.

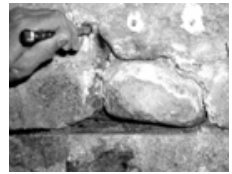

Figure 8: Inspection phases. 


\subsubsection{Local inspection}

Local inspections were carried out in order to control the plaster (Fig. 7) or the walls connection, important parameter for the seismic behaviour of the structure. The survey of the section was carried out by local inspection, taking off a few stones in order to visually investigate the wall texture (Fig. 8), redraw the inner aspect of the wall (Figs. 9-10), sample stones and mortar for laboratory testing.

The observation of the section morphology explained the peculiarity of the previous tests. In fact, St Andrew's masonry, apparently in stone blocks, revealed the presence of internal voids and poor material between the two leaves (Fig. 10). Flat jack tests were carried out on the external leaf with a higher mechanical characteristic, but the sonic tests carried out by transparency detected the internal irregularity.

In contrast, the Immacolata church, with an even more irregular external texture, had a better connection between the leaves (Fig. 9).

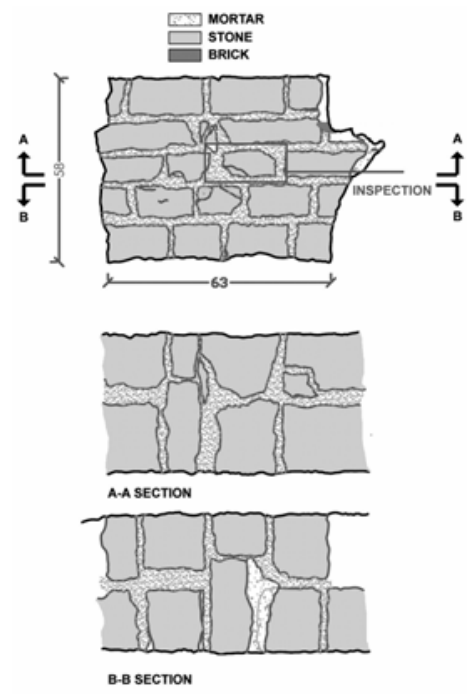

Figure 9: Immacolata: section reconstruction
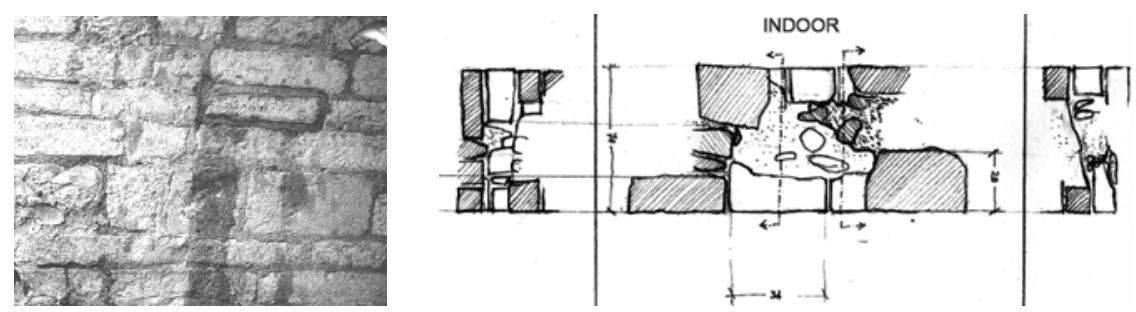

Figure 10: Immacolata church: crack pattern of the façade and detail of a tie rod find after a local inspection of a crack. 


\subsubsection{Material properties}

The sampled stones and mortars were tested in laboratory. The mortars were submitted to chemical and physical analyses. The binder was separated from the aggregate by thermal attack and the grain size distribution was calculated. The results of the chemical analyses show that most of the mortars were similar, the binder being hydrated lime. The stones belonged to several lithotypes but limestone was the most frequent one.

\section{Vulnerability analysis and damage interpretation}

The interpretation of the crack patterns and the evaluation of the intrinsic vulnerability, also through the analysis of the transformations that the churches had suffered during the last century, were useful to distinguish the damage caused by the earthquake from that previously present on the constructions.

In Fig. 11 the crack pattern of the Immacolata church façade is represented. The church shows the activation of a series of collapse mechanisms connected to a transversal vibration of the hall. On the central part of the façade a series of cracks are visible corresponding to the openings (connected to in-plane seismic action). Inside, a longitudinal crack on the vault is present correlated to an outof-plane displacement of the lateral free wall, which attains the maximum value above the height of the existing tie-rods.

The church location (connected to the presence of other buildings on two sides) and the structural transformations, carried out after 1929, have increased the vulnerability of the church, involving the crack patterns observed during the post-earthquake inspections.
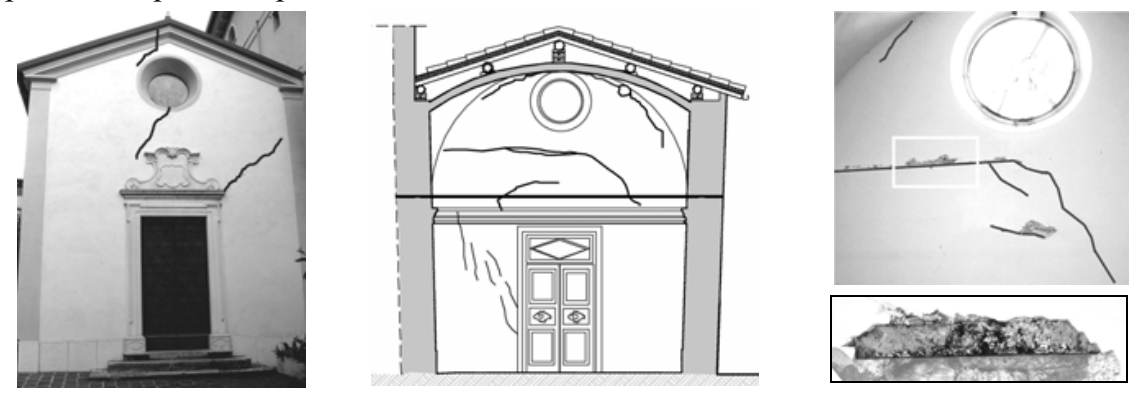

Figure 11: St Andrew's. Masonry texture and reconstruction of the section.

The lack of the original lateral constraint (masonry buttress and the bailey) favoured the activation of the previously described damage mechanisms (Fig. 3). The thrust, provided by the adjacent building, was not balanced adequately: the existing steel tie-rods are not able, in fact, to create a real contrast, because their position reduces the effectiveness of these aseismic devices. The steel tie rod, in correspondence of the façade, is not positioned in the masonry wall axis (situation structurally more accurate) and it seems too high to limit an in-plane mechanisms. On the other hand, the tie rods in correspondence of the barrel vault are too low to absorb the vault thrust correctly. It is worth noticing, moreover, 
that the roof loads directly the vault with irregular supports, increasing the vulnerability of this macroelement.

More complex is the situation on St Andrew's church (Fig. 12), due to the several interventions during the centuries. The surveys have singled out that the seismic event has caused a limited crack pattern, increasing, in many cases, historic failures.

In detail, the Authors have focused their attention on the widespread crack state of the central nave vaults of the presbytery and of the apse. The crack pattern on the vaults is strictly connected to the presence of a reinforced concrete slab on the vaults extrados. The stiffness of this structural element determines a shift of the stress state on the stiffer structure (reinforced concrete slab), decompressing the original masonry vault. The reduction of the compression state level in the vaults, in occasion of the seismic action, caused a widespread and articulate crack pattern which cannot be associated with a defined collapse mechanism, but with the presence of this new vulnerability indicator. Moreover, the damage surveyed in the transversal arches of the aisles can be correlated to the major vulnerability of these elements in comparison to the transversal arches of the central nave. They are, in fact, the only elements of the church without steel tie-rods.

The bell tower, finally, built after the church, showed, from the beginning of its construction, a clear vulnerability for the interaction with the church. On fact, it has caused an increase of the compressive stress on the original church walls. The masonry arches of the church in fact, support the southwest wall and part of the northwest wall of the belfry. Such structural situation has determined a significant load increase, especially on the second column of the presbytery and on some parts of the apse and presbytery walls. It is worth noticing that the presbytery column showed, immediately after the belfry construction, an increase of the compressive stress level and, therefore, it was object of a retrofitting intervention, based on the insertion of a steel confinement on the column.

The crack pattern observed, therefore, although increased by the earthquake, must be studied through a multidisciplinary approach able to take into account the historic transformations and the recent retrofitting interventions (1962). This should be carried out, in order to evaluate the seismic behaviour of the church and to define the most appropriate seismic improvement intervention.
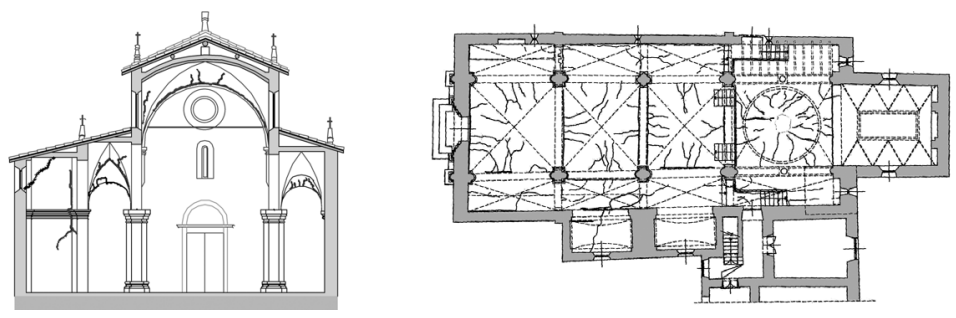

Figure 12: St Andrew's. Crack pattern of the vaults. 


\section{Remarks about the intervention}

From the observation of the damage and collapse mechanisms activated by the earthquake it was found that, the vulnerability of churches depends on deficiencies and on building details. As a consequence of this analysis the design approach for the seismic upgrade has been individuated in order to determine a reduction of seismic vulnerability by eliminating the major construction defects and carried out an effective seismic protection. For each of the two churches, starting from the vulnerability analysis, a seismic upgrading proposal was identified based mainly on the installation of minimum e-seismic elements in order to preserve the architectural features of the monuments.

In order to check the safety level of the church (local mechanisms) and the effectiveness of the interventions proposed, it has been adopted a kinematic approach (Heyman [7]), based on the equilibrium limit analysis.

The Italian OPCM 3431/2005 seismic code [8] proposes a displacementbased method for the assessment of local mechanisms in case of ordinary buildings. Various design and verification codes (Eurocode8 [9], ATC40 [10]), have adopted the idea of the performance-based design and of the non-linear response of the building. In the OPCM 3431/2005 seismic code, the structural capacity of the local mechanism is evaluated through the equilibrium limit analyses (kinematic theorem). Peculiarly, kinematic analysis is recommended for the assessment of the horizontal acceleration that activates the mechanism and for the estimation of the ultimate capacity in terms of horizontal displacement.

Unfortunately, in the case of monumental heritage, the OPCM 3431 seismic code [8] does not propose a specific methodology, even though it points out the need for a quantitative evaluation. Nevertheless, the National "Guidelines to the application of the Technical Code, for the peculiar needs of conservation of the cultural heritage", in the specific case of churches, considers this kind of procedure.

In Annex 11.C, OPCM 3431/2005 [8] proposed two procedures: linear kinematic analysis (in which the comparison is in terms of horizontal acceleration that activates the mechanism) and non-linear kinematic analysis (in which the ultimate capacity is in terms of horizontal displacement). In both procedures, the first step is the evaluation the seismic coefficient $\alpha_{0}$ that induces the loss of equilibrium; it is obtained from the principle of virtual works, using the equation [11.C.1] in Annex 11.C reported in (1), applied to the kinematic chain of blocks

$$
\alpha_{0}\left(\sum_{\mathrm{i}=1}^{\mathrm{n}} \mathrm{P}_{\mathrm{i}} \delta_{\mathrm{x}, \mathrm{i}}+\sum_{\mathrm{j}=n+1}^{\mathrm{n}+\mathrm{m}} \mathrm{P}_{\mathrm{j}} \delta_{\mathrm{x}, \mathrm{j}}\right)-\sum_{\mathrm{i}=1}^{\mathrm{n}} \mathrm{P}_{\mathrm{i}} \delta_{\mathrm{y}, \mathrm{i}}-\sum_{\mathrm{h}=1}^{\mathrm{o}} \mathrm{F}_{\mathrm{h}} \delta_{\mathrm{h}}=\mathrm{L}_{\mathrm{fi}}
$$

where the term's meaning is that given in the seismic code. Briefly, in order to obtain the activation multiplier $\alpha_{0}$, it is necessary to take into account: (i) the $n$ dead weights applied in their centres of gravity to the blocks $\left(\mathrm{P}_{\mathrm{i}}\right)$ and their virtual horizontal and vertical displacements $\left(\delta_{\mathrm{x}, \mathrm{i}}, \delta_{\mathrm{y}, \mathrm{i}}\right)$; (ii) the $m$ weights $(\mathrm{Pj})$, which are not borne by the macroelement, but able to induce horizontal seismic actions, because their masses are not effectively connected to other structural elements, 
and their virtual horizontal displacements $\left(\delta_{\mathrm{x}, \mathrm{j}}\right)$; (iii) the $o$ external actions $\left(\mathrm{F}_{\mathrm{h}}\right)$, such as thrust of roof, arches and vaults; the possible internal actions, $\mathrm{L}_{\mathrm{fi}}$ (friction sliding, interlocking, etc.). So, one can evaluate the virtual displacements by applying an infinitesimal deformation to the kinematism; for example, if an infinitesimal rotation $\theta_{\mathrm{k}}$ is applied to the block $\mathrm{k}$, the rotations of the other blocks are obtained by the kinematic mechanism, only considering geometry (even by graphical procedures), and the same applies for the displacements of each relevant point.

The horizontal spectral acceleration $\mathrm{a}_{0} *$ that activates the mechanism is given by the equation [11.C.4], reported in (2), by the horizontal seismic force divided by the effective mass $M^{*}$.

$$
a_{0}^{*}=\frac{\alpha_{0} \sum_{i=1}^{n+m} P_{i}}{M^{*}}
$$

The effective mass $M^{*}$ can be evaluated through the virtual displacements of the application points of the loads, as a mode of vibration [11.C.3]. Its value is less than the total mass of the system, and it takes into account, as in the overall verification method in which the $1^{\text {st }}$ mode is accounted for, the part dynamically excited by the seismic action.

The safety-check for collapse limit state (coincident with the ultimate limit state in the OPCM 3431/2005 law [8]), through the linear kinematic analysis, consists of the comparison between the horizontal acceleration $\mathrm{a}_{0}{ }^{*}$, that represents the structural system capacity, and of the acceleration $\mathrm{a}_{\mathrm{CLS}}$, that is the earthquake demand. The value of $\mathrm{a}_{\mathrm{CLS}}$ is defined on the elastic response spectrum of the earthquake, as in paragraph 3.2.3 of OPCM 3431/2005, reduced by an inelastic factor $\mathrm{q}$, equal to 2 , that takes into account the non-linearity of the structural system, in correspondence with period $\mathrm{T}=0$, and amplified to consider the effect of the whole building, using the equation [11.C.8] in Annex 11.C reported in (3).

$$
\mathrm{a}_{0}^{*} \geq \mathrm{a}_{\mathrm{CLS}}=\frac{\mathrm{a}_{\mathrm{g}} \mathrm{S}}{\mathrm{q}}\left(1+1.5 \frac{\mathrm{Z}}{\mathrm{H}}\right)
$$

where $\mathrm{a}_{\mathrm{g}}$ is the PGA reference value, $\mathrm{S}$ is the soil coefficient, $\mathrm{Z}$ is the height of the mechanism above the soil foundation (it may be referred to the mass centroid or, if it is connected to the building in different points, to the centroid of the hinges); $\mathrm{H}$ is the building height (as defined in paragraphs 3.2.1 and 3.2.3 of OPCM 3431/2005). The safety check through the non-linear kinematic analysis, for the collapse limit state, implies the evaluation of the spectral displacement value $\mathrm{d}_{\mathrm{u}}{ }^{*}$, that represents the ultimate capacity of the structure and comparison to the value $\Delta_{\mathrm{d}}$, being the earthquake demand in terms of displacement.

For each church, on the basis of the diagnosis carried out, the horizontal acceleration $\mathrm{a}_{0} *$, before and after the intervention correlating this value with the earthquake demand as defined by the Regional Technical Code ( $\mathrm{n}^{\circ} 36-$ 21/03/2005 - Lombardy Region) was evaluated.

The peculiar damage pattern of the Immacolata church determined the adoption of a seismic upgrade intervention based on the insertion of a buttress in correspondence of the façade and the lateral wall to contrast the vault thrust. 
Table 1: Horizontal acceleration values, before and after the seismic upgrade intervention.

\begin{tabular}{|l|c|c|}
\hline \multicolumn{1}{|c|}{ Collapse mechanism } & $\begin{array}{c}\mathbf{a}_{\mathbf{0}} *\left[\mathbf{m} / \mathbf{s}^{\mathbf{2}}\right] \\
\text { (before intervention) }\end{array}$ & $\begin{array}{c}\mathbf{a}_{\mathbf{0}} *\left[\mathbf{m} / \mathbf{s}^{\mathbf{2}}\right] \\
\text { (after intervention) }\end{array}$ \\
\hline In-plane mechanism of façade & 1.47 & 3.33 \\
\hline Transversal response & 0.68 & 1.96 \\
\hline Overturning of the façade & 2.45 & 2.45 \\
\hline Triumphal arch & 1.27 & 1.27 \\
\hline
\end{tabular}

In Table 1, the values of the horizontal acceleration, before and after the seismic upgrade intervention, are reported.

The comparison of the collapse multiplier values shows a significant increase of the structural safety of damage mechanisms, directly involved by the intervention; nevertheless, the buttress insertion does not change the seismic behaviour of the other macroelements. The intervention is proposing traditional technical solution, structurally efficient, that, however, it was not used in the last fifty years, with the exclusion of rare cases (i.e. S. Angelo dei Lombardi church designer: Prof. A. Giuffrè). It is, obviously, a highly visible solution (although "visible" is not always synonym of "invasive"); but, in this case, the analysis of the church transformations and the pre-existence of these elements justify the insertion of the two buttresses, not only for the structural safety, but also respectful of the architecture.

Also for St Andrew's church, the absence of an overall behaviour had determined the adoption of a structural model based on the analysis of local collapse mechanisms for the different macroelements individuated in relation to the diagnosis carried out. The interventions are finalized both to repair the occurred damage and to eliminate the vulnerability sources. It seems clear from the analyses carried out, that the churches have suffered a series of "restoration" interventions, which have increased the seismic vulnerability. Nevertheless, the transformations realized are non-reversible. Therefore, if in theory a more efficient structural behaviour could be possible re-establishing the original configuration, it is, in practice, impossible because the changes could be too invasive.

In order to improve the seismic response of the transversal arches of the aisles, the insertion of steel tie-rods has been designed. This intervention allows the increasing of the horizontal acceleration from $0.981 \mathrm{~m} / \mathrm{s}^{2}$ to $2.64 \mathrm{~m} / \mathrm{s}^{2}$.

For the nave vaults and the presbytery walls (in correspondence of the belfry), the Authors have planned the repair of the crack patterns through gout injections. Although the seismic improvement of this kind of solution cannot be synthesized in the value of a collapse multiplier, its effectiveness is connected to a better continuity in the masonry.

\section{Conclusions}

The research has shown the importance of a global approach in the structural analysis of historic buildings. The available information on historic evolution, 
material characterisation and on-site survey could help in the damage interpretation but also in the structural analysis.

Furthermore, the detailed knowledge of the building allows interventions directly finalized both to repair the occurred damage and to eliminate the vulnerability sources.

\section{Acknowledgements}

The Authors wish to thank Mb Studio, directed by Architect M. Biasin and the parish priest who supported the experimental investigation. The research was cofinanced by the National projects RELUIS. C. Arcadi, M. Antico, L. Cantini, M. Cucchi, M. Iscandri and C. Schiaffi are gratefully acknowledged for their technical support; many thanks are also due to the students D. Beacco, C. Ranzenigo, R. Sartori, C. Savani.

\section{References}

[1] Binda, L., Anzani, A., Cantini, L., Cardani, G., Tedeschi, C. \& Saisi, A., On site and laboratory investigation on some churches hit by a recent earthquake, in order to assess the damages to materials and structures, Proc. $1^{\text {st }}$ Int. Conf. on Restoration of Heritage Masonry Structures, Cairo, 2006.

[2] Binda, L., Baronio, G., Gambarotta, L., Lagomarsino, S. \& Modena, C., Masonry constructions in seismic areas of central Italy: a multi-level approach to conservation, Proc. 8NAMC (North American Masonry Conf.), pp. 44-55, 1999.

[3] Binda, L., Cardani, G. \& Saisi, A., Application of a multidisciplinary investigation to study the vulnerability of Castelluccio (Umbria), Proc. $9^{\text {th }}$ STREMAH Int. Conf. on Structural Studies, Repairs and Maintenance of Heritage Architecture, pp. 311-322, 2005.

[4] Binda, L. \& Saisi, A., State-of-the-art of the research on historic structures in seismic areas in Italy, Progress in Structural Engineering and Materials, 7(2), pp. 71-85, 2005.

[5] Doglioni, F., Moretti, A. \& Petrini, V., Le chiese e il terremoto (The churches and the earthquake). Trieste: Ed.LINT.320 pp.1994. (in Italian).

[6] Lagomarsino, S. \& Podestà, S., Damage and vulnerability assessment of the churches after the Molise earthquake (2002), Earthquake Spectra, 20, Special Issue I, pp. 271-283, 2004.

[7] Heyman, J., The stone skeleton, International Journal of Solids and Structures, 2, pp. 249-279, 1966.

[8] OPCM, n.3431, May $3^{\text {rd }}$ 2005. Official Bulletin n. 107, 2005 (in Italian).

[9] Eurocode 8: Design of structures for earthquake resistance - Part 1: General rules, seismic actions and rules for buildings, prEN 19981:2003E. CEN, Brussels, 2003.

[10] ATC40, Seismic evaluation and retrofit of concrete buildings. Volume 1, Applied Technology Council, publication No.40, prepared for the Seismic Safety Commission for the State of California, 1996. 